\title{
Pemanfaatan Video Pembelajaran Karate INKANAS Menggunakan Aplikasi Adobe Premier Pro 2019
}

\author{
Amru Yasir ${ }^{1}$, Sabrina Aulia Rahmah ${ }^{2}$, Jovi Antares ${ }^{3}$ \\ ${ }^{1,2,3}$ Teknologi Informasi, Universitas Dharmawangsa
}

\begin{tabular}{l}
\hline Article Info \\
\hline Article History: \\
Received Jun $12^{\text {th }}, 2021$ \\
Revised Aug $20^{\text {th }}, 2021$ \\
Accepted Aug $31^{\text {th }}, 2021$ \\
\end{tabular}

\section{Kata Kunci:}

Video

Karate

Tutorial Teknik Karate

\begin{abstract}
ABSTRAK
Video merupakan media elektronik yang mampu menggabungkan teknologi audio dan visual secara bersama sehingga menghasilkan suatu tayangan yang dinamis dan menarik. Karate adalah olahraga beladiri berasal dari Jepang yang menggunakan tangan dan kaki sebagai alat untuk melepaskan kekuatan pukulan, serangan, dan tendangan. Karate selain sebagai olahraga tempur yang menyegarkan juga dapat melatih mental agar berani dan kuat. Kata "karate" berarti tangan kosong dan orang yang mempraktekkan karate disebut karateka. Diera digital sekarang telah banyak aplikasi pembuatan video sehingga memudahkan masyarakat dalam menyampaikan sesuatu seperti tutorial teknik dasar karate yang mana teknik-teknik karate biasanya dipraktekkan langsung oleh pelatih sehingga murid bisa saja lupa akan teknik tersebut, maka di buatlah tutorial teknik karate melalui aplikasi video guna untuk memudahkan para siswa memahami dan bisa mengulang kembali teknik -teknik tersebut di luar waktu latihan dengan sendirinya yang mana siswa tersebut hanya melihat hasil dari tutorial aplikasi video yang telah dibuat.
\end{abstract}

Copyright (C) 2021 STMIK Triguna Dharma. All rights reserved.

\author{
Corresponding Author: \\ Nama : Amru Yasir \\ Program Studi : Teknologi informasi \\ Afiliasi : Universitas Dharmwangsa \\ Email: amruyasir@dharmawangsa.ac.id
}

\section{PENDAHULUAN}

Pada masa pandemi covid-19 yang terjadi diIndonesia banyak kendala yang terjadi yang mengharuskan orang lain untuk menjaga jarak antar orang lain. Akibat dari hal ini berdampak juga terhadap sistem belajar mengajar karate yang ada di perguruan karate INKANAS. Sehingga muncul ide untuk pembuatan video latihan karate agar memudahkan siswa karate dalam memahami dan melatih ketangkasan yang bisa dilakaukan di rumah.

Video merupakan media elektronik yang mampu menggabungkan teknologi audio dan visual secara bersama sehingga menghasilkan suatu tayangan yang dinamis dan menarik. Video dapat dikemas dalam bentuk file Mp4 atau file lainnya sehingga mudah dibawa kemana-mana, mudah digunakan, dapat dijangkau audiens yang luas dan menarik untuk ditayangkan. Berbagai informasi ditawarkan dengan bentuk multimedia yang dapat menciptakan presentasi interaktif dan informatif teks, audio, video, animasi dan grafik untuk keunggulan bersaing [1]. Diera digital sekarang telah banyak aplikasi pembuatan video sehingga memudahkan masyarakat dalam menyampaikan sesuatu seperti tutorial teknik dasar karate yang mana teknik-teknik karate biasanya dipraktekkan langsung oleh pelatih sehingga murid bisa saja lupa akan teknik tersebut, maka di buatlah tutorial teknik karate melalui aplikasi video guna untuk memudahkan para siswa memahami dan bisa mengulang kembali teknik -teknik tersebut di luar waktu latihan dengan sendirinya yang mana siswa tersebut hanya melihat hasil dari tutorial aplikasi video yang telah dibuat.

Karate adalah salah satu cabang olahraga dari bela diri yang hanya menggunakan tangan kosong tanpa bantuan senjata. Olahraga ini memiliki tujuan utama, yaitu untuk mempertahankan serta melindungi diri dari berbagai ancaman serta untuk menjaga kesehatan[1]. 
Karate adalah suatu olahraga bela diri yang sangat menuntut suatu keterampilan serta teknik-teknik dan rasa percaya diri yang tinggi, agar mampu menampilkan permainan yang baik dan konsisten dalam melakukan suatu pertandingan. Dengan demikian dibutuhkan Pembina ataupun pelatih yang memahami dengan jelas tugas dan profesinya[3].

Video sebagai salah satu kemajuan teknologi telah banyak memberikan pengaruh positif dan kemajuan bagi manusia dan kebudayaannya [2]. Dengan adanya video, orang tidak lagi sulit untuk mendapatkan berbagai informasi, pengetahuan dan hiburan. Peristiwa dan kejadian-kejadian penting yang terjadi diseluruh penjuru di dunia pun bisa disaksikan secara mudah dan cepat, hal ini menjadikan dunia yang luas seakan menjadi sempit dan hampir tidak lagi dikenal dengan batas-batas waktu maupun tempat.

Beladiri banyak bermunculan,tetapi masih banyak dari mereka yang tidak memahami self defensenya,alasan terutama seseorang mempelajari beladiri adalah untuk perlindungan diri namun tidak sedikit yang berpikiran di jaman sekarang ini beladiri hanyalah sebuah olah raga aeorobik yang di bungkus dalam bentuk kombat semata dan berbagai macam rules aturan aturan yang ada serta jenjang waktu yang lama untuk mencapai sabuk hitam menjadi penyebab salah satu bagian mindset masyarakat terutama wanita untuk enggan mempelajari beladiri.jago di di arena saja dan hanya bergelar sabuk tidak cukup tetapi kita semua harus bisa membaur juga dengan keadaaan situasi di sekitar kita karena kejahatan tidak pandang bulu dan akan nekad melakukan apapun demi merampas barang kita [7].

Pukulan adalah serangan yang dilakukan dengan menggunakan tangan dan lengan sebagai komponen penyerang. Pukulan mempunyai berbagai macam jenis dan variasinya, sesuai aliran dan jenis beladiri masingmasing [4].

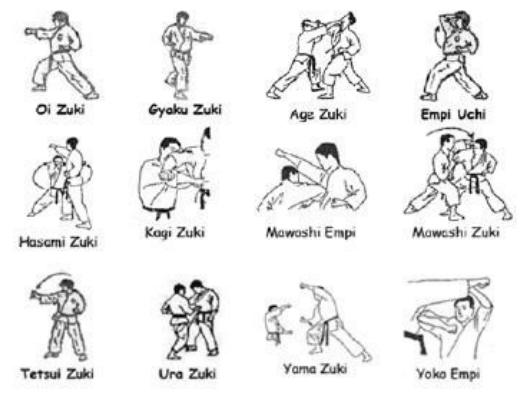

Gambar 1. Teknik- Teknik Pukulan Dasar

Tendangan adalah serangan yang dilakukan menggunakan kaki dan tungkai sebagai komponen penyerang. Tendangan merupakan salah satu teknik yang digunakan atlet beladiri untuk mendulang poin dalam kategori tanding [4].

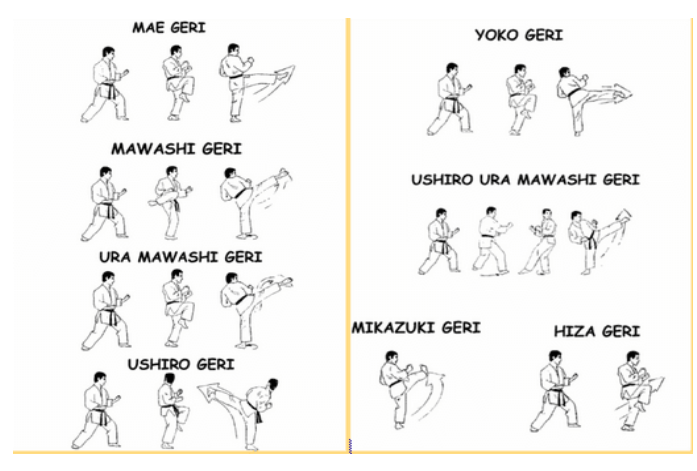

Gambar 2. Teknik- Teknik Tendangan Dasar

Selain dari itu perlu diperhatikan dalam membela diri yaitu bentuk, arah atau lintasan dari serangan lawan,posisi (sikap tangan,kuda-kuda,dan tubuh),gerak untuk membela,dan teknik tangkisan yang sesuai dengan serangan lawan [5]. Anggota badan yang dapat diperhunakan untuk menangkis adalah lengan (dengan 
satu lengan atau dua lengan dan kaki)

Olahraga bela diri merupakan suatu kebutuhan bagi kalangan masyarakat. Bela diri merupakan suatu unsur perpaduan seni, teknik, olahraga serta olah batin (spiritual) yang di dalamnya terdapat muatan nilai seni budaya masyarakat di mana seni beladiri itu lahir dan berkembang. Ada banyak cabang olahraga beladiri yang ada di Sumatera Barat beserta perguruannya, seperti cabang olahraga pencak silat, karate, taekwondo dan lainlain [6]. Beberapa perguruan pencak silat di antaranya adalah Satria Muda Indonesia, Silat Harimau, Pencak Silat Tenaga Dasar, dan Tapak Suci. Setiap perguruan beladiri mempunyai perkumpulan yang sifatnya terorganisir serta tersusun oleh suatu kepengurusan.

Olahraga Beladiri karate berkembang begitu pesat khususnya di Indonesia. Pesatnya perkembangan karate di Indonesia ditandai dengan banyaknya perguruan karate yang ada saat ini. Selain itu banyaknya pertandingan karate yang diselenggarakan di Indonesia baik dari tingkat kecamatan, kabupaten, provinsi, nasional hingga internasional semakin menunjukan perkembangan yang pesat pada beladiri karate di Indonesia [12].

\section{METODE PENELITIAN}

Dalam penelitian ini metode penelitian yang digunakan adalah metode eksperimen, dimana metode experimen merupakan metode yang menjadi bagian dari metode kuantitatif yang mempunyai ciri khas tersendiri [11], yaitu dengan adanya gerakan dasar-dasar latihan kareta. Subjek dalam penelitian ini adalah Perguruan INKANAS [Institut Karate-Do Nasional]. Target Karate Adalah Anak Kecil Yang Berumur 5 Tahun Sampai Dewasa Karena Anak Yang berumur 5 tahun sudah bisa dibentuk kepribadian yang disiplin, karakter yang baik agar menjadi bibit atlit dan untuk orang dewasa agar membentuk karakter yang lebih baik lagi dan menjadi atlit.

Teknik pengumpulan data yang digunakan yaitu dokumentasi, teknik tes dan observasi. Pada metode ini menggunakan alat seperti kamera dan flashdisk guna data yag diperoleh.

Teknik tes yang digunakan untuk memutar video yang telah dirancang dengan menggunakan adobe premier pro 2019 adalah video yang berextensi MP4, Media Player dan VLC.

Observasi yang dilakukan melakukan tinjauan langsung kepusat latihan beladiri karate inkanas dengan melihat bagaimana siswa-siswa karate latihan dan menggambarkan kedalam bentuk story board.

\section{ANALISA DAN HASIL}

\subsection{Analisis Kebutuhan Sistem}

Analisis kebutuhan sistem dilakukan untuk mengidentifikasi kebutuhan yang diperlukan dalam membangun sebuah video. Dalam tugas akhir ini dilakukan analisis kebutuhan masukan, kebutuhan proses, dan kebutuhan keluaran. Analisa sistem dilakukan untuk mengetahui kelebihan dan kekurangan dari sistem yang selama ini dijalankan serta memahami informasi-informasi yang didapat dan dikeluarkan oleh sistem itu sendiri.

Video latihan karate adalah merupakan salah satu jenis media audio visual, dan merupakan media yang paling lengkap, karena video menampilkan unsur gerak, visualisasi yang nyata, gambar, suara, dan juga banyak unsur musik sehingga menjadi daya tarik yang lebih efektif guna untuk menarik perhatian siswa didik karate.

\subsection{Konsep Pembuatan}

Untuk membuat sebuah video latihan karate, penulis terlebih dahulu membuat diagram alur agar pasepase pembuatan lebih tersusun, adapun diagram alur yang penulis buat sebagai berikut :

Tabel 1. Konsep Pembuatan

\begin{tabular}{|ll|l|l|}
\hline \multicolumn{2}{|c|}{ PRA PRODUKSI } & PRODUKSI & PASCA PRODUKSI \\
\hline 1. & Menentukan ide & & \\
2. & Script writing \\
3. & Script breakdown \\
4. & Storyboard \\
5. & Time Planning & & \\
\hline
\end{tabular}




\subsection{Pra-Produksi}

Pra produksi merupakan tahapan perencanaan dan persiapan untuk melakukan atau pembuatan video latihan karate. Dalam tahapan ini terbentuklah ide dan gagasan yang kemudian dilanjutkan dengan melakukan riset terhadap gerakan-gerakan karate, kemudian barulah menyusun kerangka, script, script breakdown, storyboard, dan jadwal produksi.

\subsection{Tahapan Pasca Produksi}

Tahapan ini adalah akhir dari penyelesaian suatu produksi, dapat dikatakan juga hasil akhir, dalam melakukan tahapan ini ada bagian-bagian yang terdiri dari beberapa langkah, yaitu antara lain :

\section{Editing And Audio}

Proses pengeditan pada hasil video tutorial karate berbasiskan video yang telah dibuat. Dengan mensortir bagian-bagian video dan audio yang tidak diperlukan akan dibuang dan juga dilakukan penambahan efek-efek visual untuk mempercantik tampilan sebuah video dengan menggunakan efek tambahan audio.

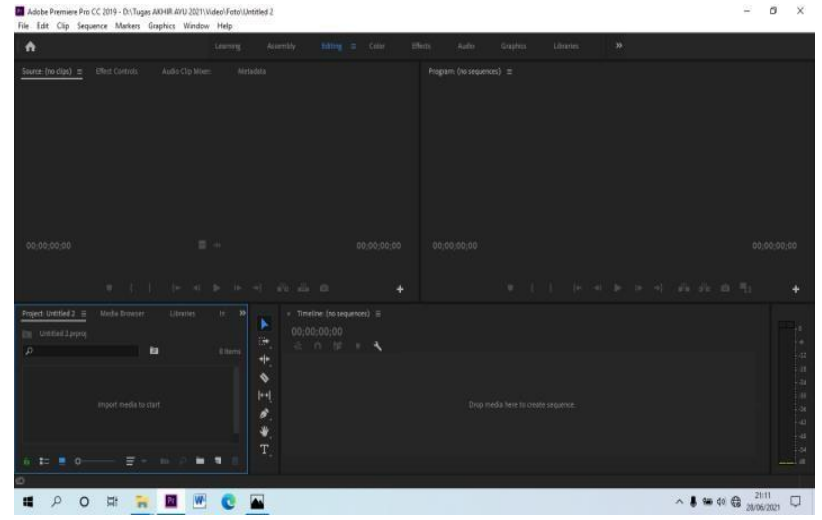

Gambar 3. Tampilan Kerja Adobe Premiere Pro

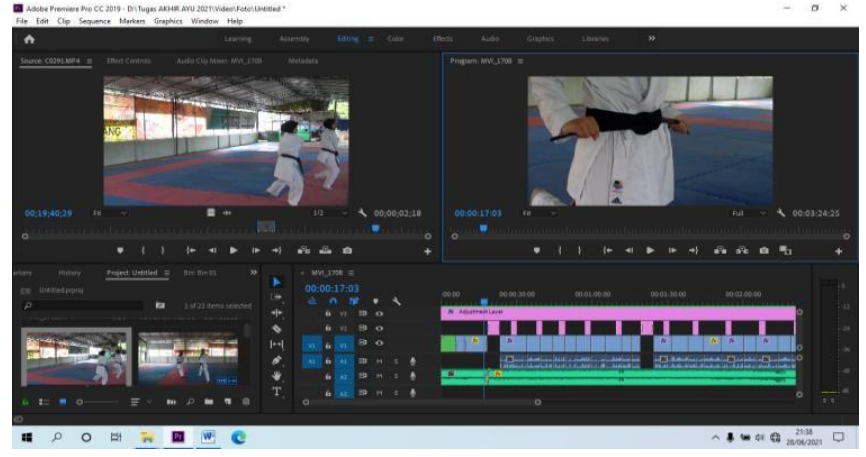

Gambar 4. Persiapan Latihan 


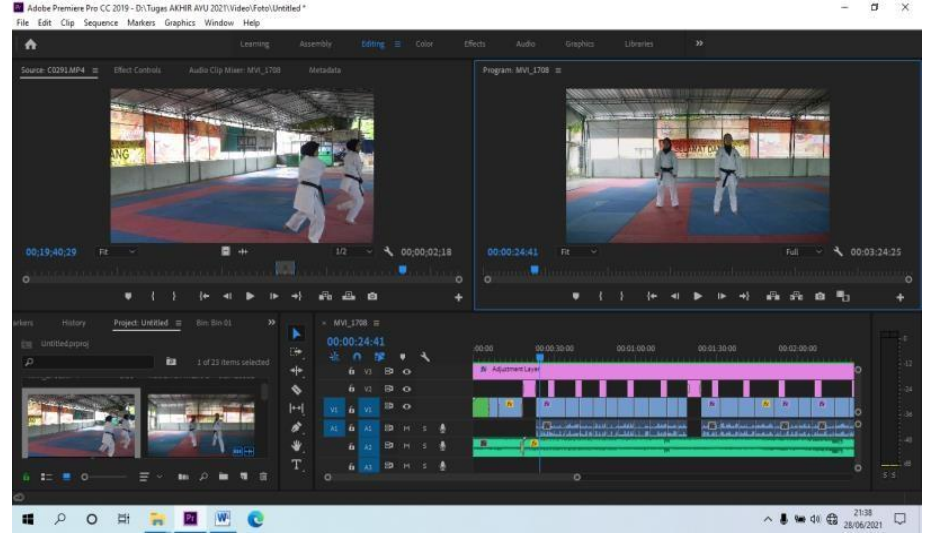

Gambar 5. Persiapan Untuk Memulai Latihan

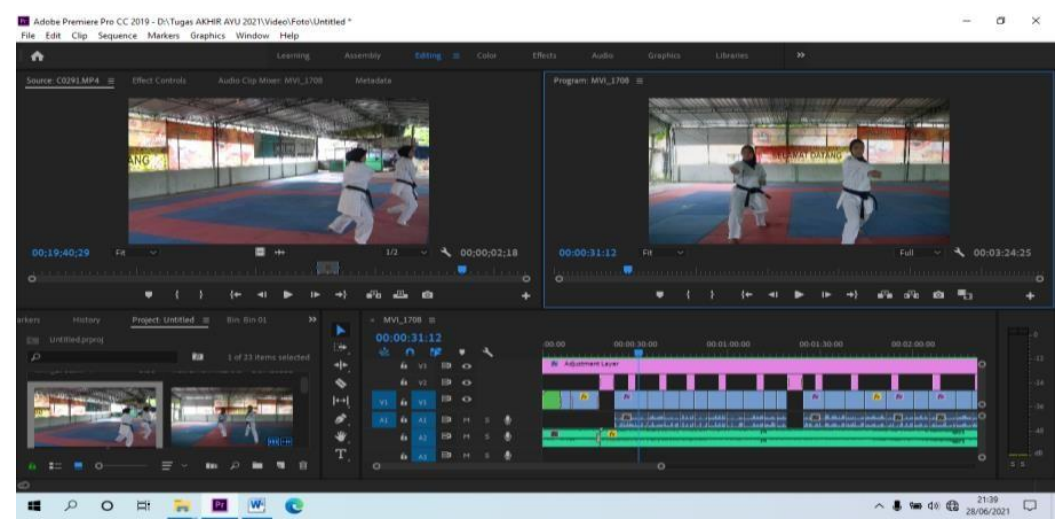

Gambar 6. Pengambilan Pukulan Arah Depan

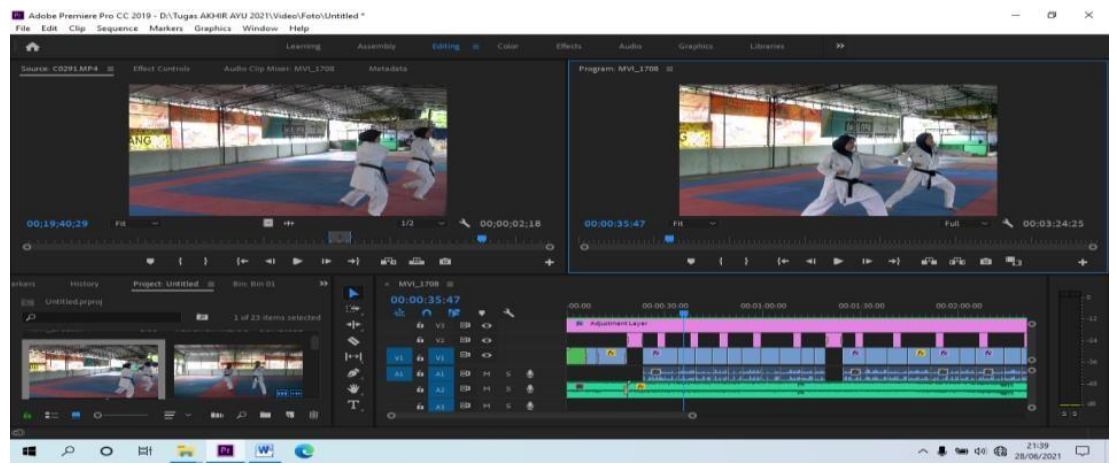

Gambar 7. Pengambilan Pukulan Arah Samping

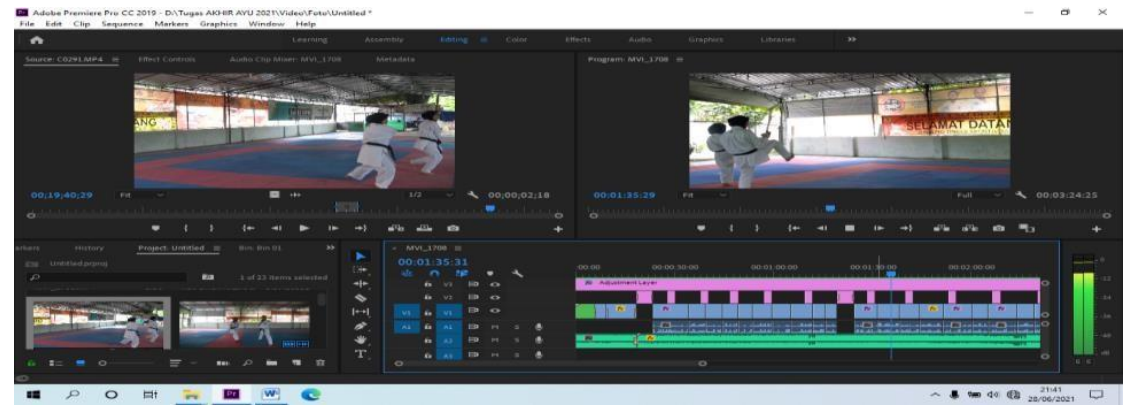

Gambar 8. Pengambilan Tendangan Arah Samping 


\section{Rendering}

Rendering merupakan proses akhir dari pada pengeditan video dimana audio dan video di kombain menjadi satu dalam sebuah video.

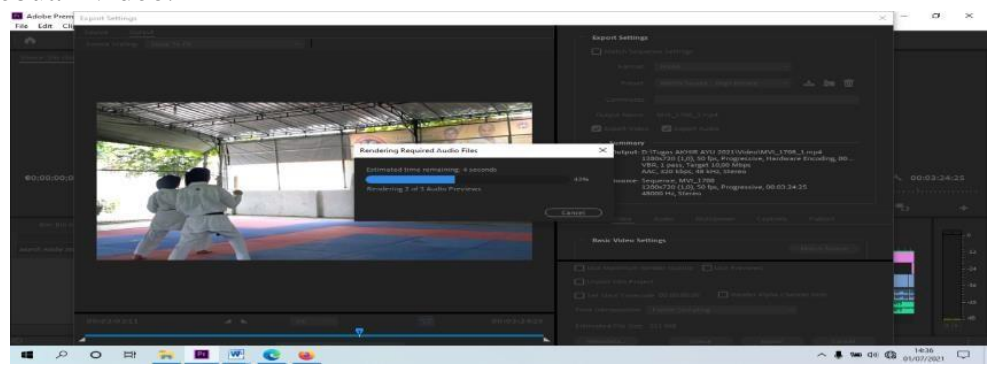

Gambar 9. Tampilan Export Pada Adobe Premiere Pro

\section{KESIMPULAN}

Dalam proses pembelajaran ada unsur penting yaitu penerapan media. Pemilihan media video memberikan manfaat yang besar dalam penyampaian pesan untuk media pembelajaran. Media video merupakan media pembelajaran yang paling tepat dan akurat dalam menyampaikan pesan dan akan sangat membantu pemahaman peserta didik. Dengan adanya media video, peserta didik akan lebih paham dengan materi yang disampaikan pendidik melalui tayangan sebuah film yang diputarkan. Unsur-unsur yang terdapat dalam media video seperti suara, teks, dan grafik. Dengan adanya media video tutorial karate peserta didik mampu mencapai kemampuan dalam ranah kognitif, afektif, psikomotorik dan meningkatkan kemampuan interpersonal.

Pengaruh yang ditimbulkan akibat penerapan video pembelajaran terhadap hasil belajar siswa menunjukkan pengaruh yang sangat tinggi.

\section{REFERENSI}

[1] Abdi (2019). Karate [Lengkap] Pengertian,Sejarah,Teknik,Peraturan,Manfaat Diakses Dari https://www.materiolahraga.com/2018/05/karate-lengkap.html

[2] Busyaeri,A., Udin,T., Zaenuddin,A. (2016) Pengaruh Penggunaan Video Pembelajaran Terhadap Peningkatan Hasil Belajar Mapel IPA Di Min Kroya Cirebon . Al Ibtida: Jurnal Pendidikan Guru MI Vol 3, No 1 (2016)

[3] Purba,P.H., (2016) Meningkatkan Keterampilan Dasar Siswa Dalam Melakukan Tendangan Mae Geri Beladiri Karate Melalui Teknik Fading Pada Siswa Kelas VIII Smp Negeri 1 Sidikalang Jurnal Ilmu Keolahragaan Vol. 15 (1), Januari - Juni $2016: 56-66$

[4] Muhammad Nur Rifqi (2016) Pengembangan Samsak Elektik Berbasisflip Flop Acak Cabang Olahraga Beladiri ( Skiripsi) Diakses Dari https://eprints.uny.ac.id/42336/1/Muhammad\%20Nur\%20Rifqi.pdf

[5] Purba,P.H., (2015) Pembelajaran Kihon Dalam Olahraga Bela Diri Karate Volume 14 Nomor 2, Juli -Desember 2015: 57-64

[6] Hadjarat Hartono . (2008) "Pembinaan Klub Olahraga Karate Di Gorontalo". Semarang: Tesis,Program Pascasarjana Program Studi Pendidikan Olahraga Unnes,hal.16.

[7] Nugraha Denny Novian,S.Sn.,M.Sn,. Dkk., (2019) Perancangan Visual Guide Bela Diri Praktis Wanita

[8] Penerapan Video Sebagai Media Pembelajaran. Yudianto,A. (2017.h.235) Manfaat media video (Yang dikutip dalam Prastowo,2012,h.302)

[9] Penta,Iiham Dkk,. (2013) Simulasi Digital Jilid II Kelas X. Jakarta : Kementrian Pendidikan Dan Kebudayaan

[10] Awule, M. E., Sentinuwo, S. R., \& Lumenta, A. S. (2016). Pembuatan Film Animasi 3D Menggunakan Metode Dynamic Simulation (Studi Kasus: Alramona n'Taumatta n'Talroda). Jurnal Teknik Elektro dan Komputer, 5(4), 70-79.

[11] Sugiyono. 2012. Metode Penelitian Pendidikan. Bandung: Alfabet.

[12] Faradita laela Maya, Dkk., (2019) Motivasi Mahasiswa Dalam Mengikuti Unit Kegiatan Mahasiswa Bela Diri Karate Di Universita PGRI Semarang. 